\title{
Con ternura de hijo quiere el cubano bueno a Costa Rica
}

\author{
Edelmis Cristina Reyes Quiñones \\ Profesora Asistente \\ Universidad Tecnológica de la Habana \\ Alberto Matos-Guerra \\ Profesor Auxiliar \\ Universidad Tecnológica de la Habana \\ Cuba
}

\section{Resumen}

Durante muchos años, Costa Rica fue receptora de cubanos que se vieron obligados a abandonar la tierra que los vio nacer, huyendo del yugo español y la miseria en que sumía al país. Este trabajo tiene como objetivo reflexionar sobre algunos patriotas leales y buenos que radicaban, desde 1870 hasta 1898 , en suelo tico y sus sentimientos hacia esta nación; cómo se integran a la sociedad y serán reconocidos en la educación, las artes, las letras, las ciencias, el derecho.

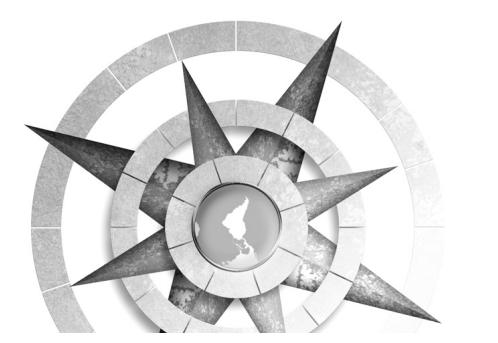

http://dx.doi.org/10.15359/tdna.33-e.10
Palabras claves: exilio cubano en Costa Rica, relaciones cubano-costarricenses, Antonio Maceo, La Mansión, José Martí, Temas de Nuestra América, Cátedra del Exilio.
Abstract
For many years, Costa Rica was a host country for Cubans forced to leave the land that saw them born, fleeing the Spanish yoke and the misery in which the country got plunged. This work aims to analyze on some loyal and good patriots who, from 1870 to 1898, came to live on Tico soil and on their feelings towards this nation; the ways they integrated into Costa Rican society and were recognized in fields such as education, arts, letters, science, law.

Keywords: Cuban exile in Costa Rica, $\mathrm{Cu}$ ban-Costa Rican relations, Antonio Maceo, La Mansión, José Martí, Temas de Nuestra América, Exile Research Group 


\section{Introducción}

Costa Rica se torna sagrada para los estudiosos e investigadores: los motivos y las razones son múltiples. Pocas son las páginas dedicadas al tema, a pesar de la profunda huella que se evidencia en esta nación. Durante muchos años, Costa Rica fue receptora de cubanos que se vieron obligados a abandonar la tierra que los vio nacer, huyendo del yugo español y la miseria en que sumía al país. Se tejieron lazos de amistad y fraternidad que llegaron más allá y se convirtieron en lazos de hermandad, en que se considera La patriótica costarricense, su segundo himno nacional. ${ }^{1}$ La melodía, tan tica como el gallo pinto, pero su letra, tan cubana ${ }^{2}$ como el congrí.

Este trabajo tiene como objetivo reflexionar sobre algunos patriotas leales y buenos que radicaban, desde 1870 hasta 1898, en suelo tico y sus sentimientos hacia esta nación; cómo se integran a la sociedad y serán reconocidos en la educación, las artes, las letras, las ciencias, el derecho. Nombres como los de Antonio Zambrana Vázquez, Ma-

1 Armando Vargas Araya, La vía costarricense, Editorial Universidad Estatal a Distancia. San José de Costa Rica, 2005. pp. 314-317.

2 Poema titulado A Cuba, fechado en 1850, por el poeta santiaguero Pedro Santacilia, quien en 1863 se casó con Manuela, hija mayor de Benito Juárez, el Benemérito de las Américas. Véase "La vía costarricense". pp. 318-323. nuel de Quesada y Loynaz, José Julián Martí Pérez, Francisco López-Calleja Pereira, Amparo López-Calleja Basulto, Enrique Loynaz del Castillo, Francisco Adolfo (Flor) Crombet Tejera, José y Antonio Maceo Grajales, María Cabrales, José María Céspedes Orellana, Ramón Céspedes Fornaris, Cayetano Acosta Nariño, Rafael Odio Zavala, entre otros, son ejemplo de ello.

\section{Breve reseña histórica}

Esta avanzada de cubanos atrajo al habanero Antonio Zambrana Vázquez, ${ }^{3}$ quien arribó el 27 de abril de 1876 a Puntarenas. Abogado, periodista, escritor, diplomático, político y extraordinario orador que fue nombrado enviado extraordinario y ministro plenipotenciario de Costa Rica en Nicaragua. Se dedicó al magisterio y le ofrecieron la presidencia de la Junta de Educación en la capital y del Ateneo de Costa Rica. Fue, además, catedrático de la Escuela de Derecho de la Universidad de Santo Tomás y magistrado de la Sala de Casación. Esto lo llevó, durante treinta años, a convertirse en la figura más influyente en la sociedad costarricense. Aceptó regresar a su país en 1911, cuando ocupó el cargo de ministro plenipotenciario en Colombia y Ecuador.

3 Armando Vargas Araya, El doctor Zambrana, San José de Costa Rica, EUNED, 2006.
192 Con ternura de hijo quiere el cubano bueno a Costa Rica Edelmis Cristina Reyes Quiñones Alberto Matos Guerra

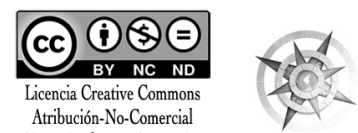


Murió el 27 de marzo de 1922, en La Habana, siendo Costa Rica su segunda patria.

En febrero de 1878 llegó a Costa Rica el Mayor General Manuel de Quesada y Loynaz, miembro prominente de la sociedad de la Isla y figura distinguida de la política cubana. Su casa fue un centro de atracción para las familias de la sociedad, en la cual hallaron una acogida sincera y una cordialidad constante de parte de aquella familia emigrada que había escogido este país por la simpatía y el afecto.

Tuvo un amigo costarricense, militar como él y alto representante de la sociedad y del gobierno, el General de División don Pedro Quirós Jiménez, vicepresidente de la República, comandante en jefe del ejército y miembro de la Directiva del Banco de Emisión de Crédito. Amistad muy íntima y bien compartida unió a ambos caballeros. La similitud de carreras, el gran conocimiento que de los problemas de orden político tenían y las circunstancias de vivir en un mismo vecindario, vinieron, no solo a los militares, sino a sus respectivas familias.

La hija del General Quesada, doña Hortensia de Quesada y de Quijano, una joven hermosa que compartía las veladas en su casa con las hijas de don Pedro Quirós. La amistad de los generales Quesada y Quirós se consolidó a manos de su sobrino Don Juan Bautista, quien había regresado de Europa en 1876, una vez terminada su educación en Inglaterra. En casa de su tío conoció a la familia del General cubano. El joven preparaba proyectos para servir a la causa cubana, aquella que era ya suya al proteger a los emigrados.

El general Quesada trabajó como superintendente de Ferrocarriles, cuando Costa Rica batallaba la conexión del Caribe con el Pacífico por vía férrea. Murió en la pobreza, el 30 de enero de 1884. Los masones costarricenses cubrieron los gastos de su entierro.

Cuando el cubano tenía que exiliarse hacia tierras donde un clima de libertad le permitiera perfilar sus planes y combinar sus acciones, Costa Rica abrió las puertas de su cordialidad, de su simpatía y de su cariño a los más destacados jefes de la insurrección.

\section{Antonio Maceo Grajales}

Entre los hombres insignes hay que destacar a Antonio Maceo, ${ }^{4}$ el hombre

4 José Antonio de la Caridad Maceo Grajales (18451896). Conocido como "El Titán de Bronce" por su portentosa trayectoria guerrera y su condición de mulato, alcanzó en la Guerra de los Diez Años (1868-1878) el grado de mayor general. Se destacó 
de la Protesta de Baraguá, ${ }^{5}$ el líder más popular, admirado y querido por los cubanos; era hijo de una familia de patriotas $^{6}$. Había recorrido Jamaica, Haití, República Dominicana, Honduras, Estados Unidos, México, Panamá y Perú.

como táctico militar y por su intransigencia revolucionaria ante la Protesta de Baraguá, en marzo de 1878 , contra el pacto que puso fin a aquella contienda. En la guerra de 1895, con el grado de lugarteniente general, participó en la campaña invasora a Occidente. Cayó combatiendo en San Pedro, provincia de La Habana, el 7 de diciembre. Centro de Estudios Militares de las FAR. Biografías. ob. cit. t. I. pp. 254- 259.

5 Se conoce así la decisión en contra del Pacto del Zanjón, expresada por Antonio Maceo, en entrevista sostenida con el general español Arsenio Martínez Campo en los Mangos de Baraguá, en la provincia de Oriente, el 15 marzo de 1878. Durante la misma, Maceo condenó los acuerdos del Zanjón y reafirmó su decisión de continuar la lucha por la liberación nacional.

6 La extensa prole de los Maceo comienza a formarse por la descendencia que surge del matrimonio de Marcos Maceo con su primera esposa Amparo Téllez, con la cual tuvo seis hijos, que murieron todos en las luchas por la independencia. En una segunda unión, con Mariana Grajales tuvo cuatro hijos de una relación anterior nacieron diez vástagos: Antonio de la Caridad (1845-1896), María Baldomera (1847-1893), José Marcelino (1849. 1896), Rafael (1850-1882); fueron bautizados como naturales de Mariana y Marco, pues no se habían casado. En 1851 contrajeron matrimonio. Les siguieron Miguel (1852-1879), Julio (18541870), Dominga de la Calzada (1857-1940), José Tomás (1857-1917), Marcos (1860-1902), María Dolores (falleció a los 15 días de nacida). De los Maceo varones sólo sobrevivieron a las contiendas independentistas Tomás y Marcos. Ver: Torres-Cuevas, Eduardo. Antonio Maceo. Las ideas que sostienen el arma. Editorial de Ciencias Sociales. La Habana. 1995. p.10.
En 1881 visitó Costa Rica por vez primera y le agradó su gente. Regresó en febrero de 1891, y su estancia duró hasta marzo de 1895, estableciendo relaciones con todo tipo de personas, políticos y revolucionarios, intelectuales, profesionales, estadistas, periodistas y militares. ${ }^{7}$

Las negociaciones con el gobierno para fundar una colonia sufrieron las demoras burocráticas naturales, Costa Rica ${ }^{8}$ era un país donde predominaba el sentimiento racista; los descendientes de africanos llegaban como braceros, y estaban limitados a las costas y a las plantaciones bananeras en labores infrahumanas. Sin embargo, Maceo llegó a la nación tica para fundar una colonia agrícola. Al enterarse España de ello protestó, ya que se le concedían al general tierras para colonizar en el departamento de Talamanca, cuyas costas baña el mar Caribe; por lo que presentó mediante su cónsul en este país, una reclamación, en que hacía saber que "la estadía de Maceo, con una colonia compuesta por familias cubanas, en las costas del Atlántico, la consideraba el Gobierno de Su Majestad Católica como una amenaza constante para la paz de Cuba".

7 Armando Vargas Araya. El Código de Maceo. El general Antonio en América Latina. Imagen Contemporánea. La Habana. 2012. pp.2-3.

8 Eduardo Vázquez Pérez. La Mansión de Maceo en Costa Rica. 16 de diciembre de 2013.

9 José Luciano Franco, Antonio Maceo. Apuntes para una historia de su vida, La Habana, Editorial de

194 Con ternura de hijo quiere el cubano bueno a Costa Rica Edelmis Cristina Reyes Quiñones Alberto Matos Guerra

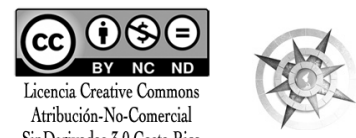


Después de sortear todos los obstáculos que exhibieron la diplomacia española, los racistas y hasta los opositores del presidente Rodríguez, a Maceo, negro y revolucionario le concedieron, como empresario, hasta 15 mil hectáreas de terreno. El presidente de la República, el licenciado José Joaquín Rodríguez Zeledón, legalizó solemnemente un contrato de colonización en el Palacio Nacional de San José, el 13 de mayo de 1891; pero, accediendo a la demanda española, le otorgó la concesión en el cantón de Nicoya, en la provincia de Guanacaste, en la costa del Pacífico.

El gobierno quiso demostrar en esta ocasión a los libertadores cubanos no sólo su espíritu de hospitalidad, sino también su apoyo moral a la justa y noble causa por la que luchaban, ofreciéndoles albergue y dándoles una forma de vivir decorosa y digna. El pueblo asimiló a Maceo y sus propósitos como parte integrante de su comunidad nacional. El presidente Rodríguez Zeledón proporcionó los medios económicos necesarios para mudar al país a las primeras cincuenta familias.

\section{Maceo y La Mansión}

Maceo, hombre reservado, gentil, culto, refinado, de pocas palabras, ejercía sin-

Ciencias Sociales/Instituto Cubano del Libro, 1973, t. II. pp. 11. gular atracción sobre cuantos cultivaban su amistad. En breve tiempo supo ganarse el respeto y la simpatía de las autoridades y del pueblo costarricense. Mientras permaneció en San José, se convirtieron en sus compañeros habituales los generales Rafael Iglesias y Juan Bautista Quirós quién le prestaba su espada de diario cuando paseaban en las noches, considerando que podía usarla, honrándola en la defensa de su amigo, en cualquier eventual caso de atentado; el general llevaba entonces consigo un pesado bastón de empuñadura de plata. Aquella espada del general Quirós, se ha convertido en histórica que hoy se halla en el Museo Nacional de Cuba.

La geografía costarricense se asemeja en algunos aspectos a Majaguabo, la tierra natal de Maceo, cerca de Santiago de Cuba. Y toda esa experiencia que acumuló en Majaguabo es la que él trasladó allí. Crea, así, un ambiente rural muy parecido al de su niñez, adolescencia y juventud, donde el amor al trabajo, a la naturaleza, al hombre que se hace con su propio esfuerzo, da lugar a una comunidad productiva extraordinariamente unida.

En 1892 comenzó el arribo a Guanacaste, que era selva pura cuando llegaron allí, donde construyeron un barracón en que vivían todos. Roturando aún

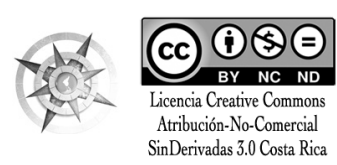


esas tierras vírgenes, ya sabían que las dedicarían al cultivo del algodón, tabaco, cacao, café, caña de azúcar y maíz. Maceo mandó a buscar a su esposa, María Cabrales, ${ }^{10}$ quién se encontraba en Kingston, Jamaica. Se separó del grupo y construye la primera casita de madera, y entre todos ellos dijeron: "Bueno, ¡ya podemos visitar la mansión de Maceo!”.

En Nicoya, con mucho esfuerzo, levantó un pueblo próspero; trasladó toda la maquinaria de un ingenio azucarero hacia ese lugar y le escribió a sus antiguos compañeros de armas y, a otros que eran gentes de trabajo fuerte en el campo, invitándoles a que se unieran porque allí había posibilidades para todos.

Maceo dejó encargado de los aspectos gerenciales y organizativos a Enrique Loynaz Arteaga, ${ }^{11}$ quien, acompañado de su esposa Juana del Castillo, supo aprovechar inteligentemente, como administrador, los pocos recursos disponibles.

10 Esposa del lugarteniente general Antonio Maceo Grajales. Ejemplo de mujer cubana en la lucha por la libertad de la patria. La historia de Cuba la contempla como una mujer de grandes valores. Nació el 22 de julio de 1847 en la finca San Agustín, situada en la jurisdicción de Jutinicú, San Luis, Santiago de Cuba

11 Qué había peleado en la guerra de 1868 y quien fuera padre del luego general Enrique Loynaz del Castillo, y abuelo de nuestra poetiza Dulce María Loynaz.

\section{José Julián Martí Pérez}

El poeta cubano José Martí ${ }^{12}$ escribió su primera alabanza a Costa Rica, -y cito textualmente al investigador y profesor Armando Vargas Araya en su libro La huella imborrable, cuando expresó: "sobre Costa Rica, industriosísima colmena, que inspira cariño por la cordialidad de sus habitantes, de los "hermaniticos", como en Centroamérica los llaman, y respeto por su laboriosidad". ${ }^{3}$

Martí procedía de los sectores más humildes y desvalidos de la sociedad cubana colonial. En virtud de sus estudios, pasó a formar parte de los más ilustrados de la emigración. La prensa y la tribuna fueron los medios utilizados por él para comunicarse intelectual y emocionalmente con las masas del exilio.

12 José Julián, Martí Pérez (1853-1895). Héroe Nacional de Cuba. Político, periodista, escritor, poeta, orador, abogado y mayor general que nació en la ciudad de La Habana el 28 de enero de 1853. Sufrió prisión y destierro a los 17 años de edad por sus ideas independentistas. Vivió en España, México, Guatemala y Venezuela, y a partir de 1881 se establece definitivamente en Estados Unidos, desde donde preparó lo que llamó la "guerra necesaria" por la liberación de Cuba. El 14 de marzo fundó el periódico Patria, el que jugó un importante papel en la preparación de la guerra. En enero de 1892 redactó las bases y los estatutos del Partido Revolucionario Cubano. Lo fundó el 8 de abril siendo electo delegado. El 11 de abril de 1895 regresó a Cuba para incorporarse a la lucha. Cayó en el combate de Dos Ríos, el 19 de mayo de ese mismo año.

13 La República Argentina en Estados Unidos, La Nación (Buenos Aires), 4 de diciembre de 1887, en OC., t. VII, p. 331.

196 Con ternura de hijo quiere el cubano bueno a Costa Rica Edelmis Cristina Reyes Quiñones Alberto Matos Guerra
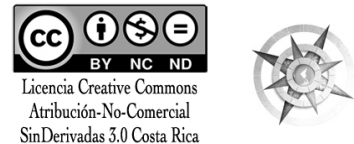
Sin haber visitado este país aún, aplicó la cualidad de la preciosa isla esmeralda, por el intenso verdor de sus campos, en un artículo sobre la Conferencia Internacional Americana (Washington, D.C., 1890), publicado el 9 de mayo en La Nación en Buenos Aires.

Vargas Araya nos demuestra algunas reflexiones de la pluma periodística del maestro, cuando expresa que resultan valiosas las percepciones que intelectuales, académicos, políticos, maestros y observadores de otras latitudes tenían sobre la identidad costarricense. Y esto supo aprovecharlo nuestro Apóstol cuando realzaba la belleza de las áreas cafetaleras, su afectuosa calidez, el mérito de la deferencia excitada por su decoro, la virtud de su fecunda labor, la solidaridad y el cariño. Describe a Costa Rica -unidos sus hijos por el fervor patriótico- por su amor a la libertad; su gente es culta por la escuela y por el libro, valiente y segura de sí misma, solidaria con los perseguidos políticos de numerosos países.

Su clarividencia se enriquece más, le anunciaba fervoroso su visita al Titán de Bronce: "mañana tomo el vapor, con rumbo a usted, y espero, sin aparato y anuncio de ninguna especie, estar en Puerto Limón". ${ }^{14}$

14 Carta de Martí y Maceo, Nueva York 25 de mayo de 1893, en OC., t. II. pp. 328 y 329.
Arribó el 30 de junio de 1893 y permanecería hasta el 8 de julio. Fue hospedado en el Gran Hotel. ${ }^{15}$ Costa Rica acogió a estas dos figuras insignes, que con el ejemplo de amor a la patria, demostrado en la lucha por la liberación de Cuba desde el exilio, cautivaron al pueblo que les ofreció su hospitalidad y solidaridad.

Martí plasmaría sus impresiones en dos crónicas: la primera "El domingo en San José", ${ }_{16}^{16}$ que nace del ambiente de la ciudad y sus gentes, y la segunda, "La Parranda" ${ }_{17}$ en donde describe los valores y las costumbres autóctonas del pueblo.

Todo lo escudriñaba con su aguda mirada, a su paso por las calles de la capital mientras se trasladaba con el general Maceo y el doctor. Antonio Zambrana. Luego tomaría su pluma para dejar constancia cuando escribiera:

[...] de seda es por dentro, y de canapé de oro, la casa que aún muestra en las afueras la ventana ceñuda y el portón colonial... La cáscara aun la oprime, pero ya aquello es república.

15 Edificación de tres pisos, propiedad de la firma Colombo £ Gallo, ubicado junto al mar frente a la isla Quiribrí (La Uvita).

16 Armando Vargas Araya, La huella imborrable. pp. 30 y 31.

17 Mario Oliva Medina, José Martí. pp. 41y 42. 
Vive el hombre de su trabajo y piensa por sí. Y cae en brazos de todos, el cubano que va a Costa Rica. Pasa un hombre fornido por la calle: ni rechaza ni lisonjea, pero lo saludan todos: habla cortés con una ventana suntuosa: -salvó en día y medio el camino de tres, y se lo admiran campesinos y ministros: ponen mesa de patria los cubanos leales, de Oriente y Poniente, y le dan la cabecera. ${ }^{18}$

Atrajo su atención el pujante ambiente cultural en la pequeña ciudad de Cartago, y por razones de afinidad política, visitó en Heredia al galeno cubano Benjamín de Céspedes, médico inspector de Sanidad en La Habana. Tenía tres años de residir en la ciudad de las flores y había comenzado una campaña de divulgación sobre literatura, filosofía, medicina y sociología.

En el hotel recibió la visita del joven de 18 años, José Rafael Pochet Lacoste, quien a nombre de la asociación Los Estudiantes, le solicitó en el Colegio de Abogados, el 6 de julio de 1893, que pronunciara una conferencia. Martí acudió y no sólo apeló a la inteligencia de su auditorio, sino que tocó las fibras más íntimas de la sensibilidad nacional con

18 José Martí, El Heraldo de Costa Rica, 7 y 8 de noviembre de 1893. Artículo sobre Antonio Maceo. imágenes literarias que despertaron los sentimientos y emociones colectivas largamente soterrados en el subconsciente del pueblo errante de la emigración, para todos los presentes resultó reveladora la necesidad de la lucha cubana por su liberación del yugo colonial español.

Esta conferencia fue célebre, ¡fue una noche memorable en la cultura costarricense!. ${ }^{19}$ Los estudiantes, al finalizar el acto, decidieron desenganchar los caballos del carruaje en que se trasladaría del Colegio de Abogados al Hotel Imperial, para tirar ellos mismos del coche en señal de sumisión y como homenaje máximo al gran hombre.

José Martí retornó a Limón, y cuando iba a saldar los gastos, su cuenta estaba pagada; y no fue ningún cubano quien la abonó ${ }^{20}$
El sábado 8 partió en un vapor rumbo a Nueva York. Al día siguiente, El Heraldo de Costa Rica, publicó la siguiente carta dirigida al poeta y director, el señor don Pío Víquez. ${ }^{21}$

19 Rafael Pochet Lacoste, José Martí, reproducido por El Pabellón Cubano, San José, Costa Rica, 16 de mayo de 1897.

20 Granda, pp.13, en Nueva York, Patria, 7 de julio de 1894. OC., t. V. p.70.

21 (1850-1899). Escritor y periodista. Gran amigo de José Martí. Fue director de la Imprenta Nacional, redactor de La Gaceta y profesor de Derecho

198 Con ternura de hijo quiere el cubano bueno a Costa Rica Edelmis Cristina Reyes Quiñones Alberto Matos Guerra
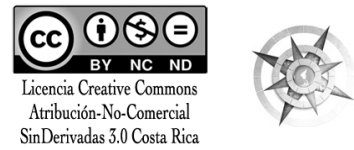
Mi amigo generoso:

Yo no puedo decir con las palabras, vestidura tantas veces del interés y la lisonja, el tierno agradecimiento con que recordaré siempre la bondad con que Costa Rica ha premiado en mí, viajero humilde y silencioso, el amor y vigilancia con que los americanos, unos en el origen, en la esperanza y en el peligro, hemos de mantener a esta América nuestra, sorprendida en su cruenta gestación, en los instantes en que por sus propias puertas muda de lugar el mundo.

\section{Más adelante expresaba}

[...]pero yo llegué ayer, insignificante e ignorado, a esta tierra que siempre defendí y amé, por culta y viril, por hospitalaria y trabajadora, por sagaz y por nueva; y Vd. salió a recibirme, con largueza de poeta, y me sentó a la mesa de la bienvenida entre los hombres cordiales de su patria. Me vi tratado como hermano por los que acaso apenas conocían mi nombre. Brillaron allí a mí alrededor el talento

Internacional. Fue nombrado presidente del Colegio de Abogados; fiscal de la corte y director del diario El Heraldo de Costa Rica. enérgico, la palabra discreta, la lisonjera amistad de quienes no la hubiesen acordado de seguro a quien no trajese el sagrado de su hogar, el respeto del huésped y el corazón limpio. Vi en torno mío a hombres plenos y buenos de la América. Y gocé, porque honran y sirven a su pueblo los que, aún fuera de justa medida, premian en nombre de él la fe en su porvenir y la fidelidad a sus ideales. Sólo de un modo puedo responder a esta merced grande: y es pedir a $\mathrm{Vd}$. y a mis amigos de Costa Rica que me permitan servirla como hijo.

Nunca olvidará a su amigo Víquez su José Martí2

En Estados Unidos publicó en Patria, el 6 de octubre de 1893, un artículo donde glorifica la belleza y la habitual vida de trabajo del pueblo costarricense: "Costa Rica que se levanta por sobre las nubes, con sus troncos de sangre serpeando por el celaje azul y derrama a las costas encendidas, por lecho siempre verde, el agua ancha y pedregosa de sus reventazones montañesas: como un himno es la república y cada hijo lleva la azada al hombro".

22 José Martí Pérez, Obras completas, t. VII, pp. 315 y 316. Carta de Martí a Pío Víquez. San José. 8 de julio 1893. El Heraldo de Costa Rica. 
Francisco López-Calleja Pereira y Amparo López-Calleja Basulto

Refiriéndose a Francisco López-Calleja Pereira, ${ }^{23}$ Martí expresó: "Allá del lado Atlántico por el río Matina, los plátanos son tan altos como la palma real, y es un cubano, que dio su sangre a Cuba, quien cría en la tierra amiga el platanal mejor".

Francisco recorrió Jamaica, viajó a Panamá, luego a Puntarenas, también vivió por un tiempo en la ciudad de Alajuela, después en Cartago y, finalmente, en San José. En el exilio, compró la finca Bonilla en el cantón de Turrialba. Puso en práctica su conocimiento como agricultor y ganadero, estableció un hospital, a donde llegaban personas de todas partes, en particular gente de bajos recursos económicos. Chico López, como lo llamaban sus amigos, se convirtió en hombre querido y popular en la zona. Murió en la ciudad de San José, alrededor de 1915..24 Fue el padre de Amparo López-Calleja Basulto, quien nació el 7 de agosto de 1870, en Nuevitas, provincia de Camagüey, Cuba.

23 Francisco López-Calleja Pereira, cubano comprometido con la independencia de su país; participó en la Guerra Grande (1868-1878) y adoptó a Costa Rica como su segunda patria.

24 Gabriel Quesada Avendaño, Primera Naturalista Costarricense: Amparo López-Calleja. Programa Garantías Ambientales. Centro de Educación Ambiental de la Universidad Estatal a Distancia, 25 de noviembre de 2010.
Amparo, quien siempre mantuvo una estrecha relación con los grupos independentistas de finales del siglo xix, fundó el Club Revolucionario Femenino Cubano en Costa Rica, organización ligada al movimiento de 1895 . Fue educada en Costa Rica y se graduó en escuelas de alta cocina de Boston, Estados Unidos. Regresó a Costa Rica en 1893 y se casó con José Cástulo Zeledón Porras el 8 de mayo de 1895. No tuvieron descendencia, por lo que ambos cuidaron a sus sobrinos y a niños discapacitados en la provincia de Cartago. Se involucró en proyectos públicos y privados, como la creación de instituciones para proteger a niños, enfermos y a ancianos. Fue reconocida nacional e internacionalmente por su interés en la historia natural y la orquideología.

José Zeledón, uno de los fundadores del Museo Nacional en 1887, fue el primer ornitólogo costarricense y discípulo de Alejandro von Frantzius, fundador de la Botica Francesa y en la cual estuvo involucrado el joven Zeledón. La Botica pasó a manos de José y se convirtió en una de las principales proveedoras de fármacos en Centroamérica. No sólo producía sus medicinas, sino que fue un importante centro de salud para los costarricenses. La Botica tuvo problemas financieros en 1920 por lo que $\mathrm{Au}$ relio López-Calleja, el hermano mayor 
de Amparo, volvió a Cuba y logró recuperar las fincas que los españoles les habían confiscado durante la guerra de Independencia. Con el dinero de la venta de las fincas, salvó la Botica Francesa de la ruina, y continuaron favoreciendo a mucha gente con sus medicinas.

José murió sorpresivamente en Turín, el 16 de julio de 1923, por lo que Amparo tuvo que asumir la conducción de la Botica Francesa. ${ }^{25}$ Desilusionada de la situación política de Costa Rica, se trasladó a Honduras, en donde continuó sus actividades sociales. Murió en Tegucigalpa, el 20 de abril de 1951. El legado biológico y social de esta extraordinaria mujer la convierten en la primera naturalista costarricense.

Retomando el artículo de Patria del 6 de octubre de 1893, Martí decía:

Con ternura de hijo quiere el cubano bueno a Costa Rica. De las gracias del mundo, Costa Rica es una, con su rocío de ciudades por el valle ameno, cada cual como mosaico en joya, y en la serena población la vida fuerte, con el hijo de médico o de juez, y su raíz en el campo, como todo hombre que quiere ser libre.

25 Diario de Costa Rica, 1923. "Fallecimiento de Don José C. Zeledón”, en Homenaje a don José C. Zeledón, San José, Costa Rica.
En Nicoya vive ahora, sitio real antes de que la conquista helase la vida ingenua de América, el cubano que no tuvo rival en defender, con el brazo y el respeto, la ley de su república. [...] Se trabaja en la Colonia un mes, y se está por San José una semana, de levita cruzada, pantalón claro y sombrero hongo. ${ }^{26}$ Las levitas son todavía de Francia, pero el pensamiento empieza a ser de América. Los jóvenes de América se ponen la camisa al codo, hunden las manos en la masa, y la levantan con la levadura de su sudor.

Martí, en su segunda visita a Costa Rica, que ocurrió entre el 5 y el 18 de junio de 1894 (no estuvo en Nicoya), apareció en compañía de Francisco Gómez Toro (Panchito), ${ }^{27}$ quien estaba a su lado desde hacía algún tiempo, y del periodista Enrique Loynaz del Castillo ${ }^{28}$.

26 José Martí, El Heraldo de Costa Rica, 7 y 8 de noviembre de 1893, artículo sobre Antonio Maceo.

27 Hijo de Máximo Gómez Báez y Bernarda del Toro (Manana).

28 Enrique Loynaz del Castillo (1871-1963) General de Brigada. Nació en Puerto Plata, República Dominicana, el 5 de junio de 1871. Sus padres, cubanos, residían en la casa destinada a la delegación revolucionaria en esa ciudad. Martí determinó enviarlo a Costa Rica, donde fue secretario del mayor general Antonio Maceo, a quien salvó la vida en el atentado de que fuera objeto el 10 de noviembre de 1894 , a la salida de un teatro en la ciudad de San José. 
El 11 de junio viajó a Puntarenas -hoy es la ciudad de Orotina-. Lo más trascendental es la fundación del Club Cubanista Revolucionario, dato importante que aporta el Dr. Mario Roberto Oliva Medina, ya que éste sería el comienzo de establecimiento de aproximadamente veinte clubes patrióticos (véase el anexo 1), con una composición heterogénea: niños, mujeres y hombres de diversos sectores sociales y países, que debían apoyar el proceso independentista de Cuba, entre 1895 y 1898. Los clubes, sus reuniones, asambleas y fiestas patrióticas se transformaron en el espacio donde pudieron expresar sus ansias de independencia. Martí fue genial en no confundir la tierra con la patria; la tierra es la que pisan nuestros pies. La patria es un compromiso que él asume con Cuba, en el cual está dispuesto a dar su vida por la liberación de ella.

Bernardo Figueredo Altúnez, hijo del patriota Fernando Figueredo Socarrás, expresó en su artículo "Recuerdos de Marti”, que lo caracterizaba una manera casi magnética de atraer a los hombres a la buena causa y que: "Era muy decidor, no hablador [...] y si tenía algún pensamiento [...] enseguida lo ponía en palabras [...] su voz era suave, no estridente ni airada, sino [...] dulce [...]". Siempre lo hacía con mesura y sin exagerar.

\section{Enrique Loynaz del Castillo}

Era el hijo del administrador de La Mansión; se unió a Maceo siendo un joven blanco aristócrata de Camagüey. Escribe el himno de combate titulado Himno a Maceo; pero éste le pidió que le cambiara el nombre y que le pusiera Himno Invasor. ${ }^{29}$ En él testifica: "De Martí la memoria dorada", y nos "guíe la fúlgida espada de Maceo, el caudillo invasor" (véase el anexo 4). Enterado el general, luego de escuchar los versos, pidió que los musicalizaran, los llevaran al pentagrama, e hicieron de aquellos un himno de combate que acompañara a la columna invasora.

Loynaz había retratado a Maceo al visitarlo [...] "calle el hombre útil, como el cañón sobre los muros, hasta que la idea incendiada lo carga de justicia y muerte". ${ }^{30}$

También el joven camagüeyano, al tiempo que se comprometía a corresponder "con el estímulo del bien que me anima

29 Creado el 15 de noviembre de 1895 en la finca La Matilde, propiedad de José Ramón Simoni el padre de Amalia Simoni el gran amor de Ignacio Agramonte, ubicado en el Municipio de Najasa, Camagüey. Este himno tuvo la misión histórica de unir las generaciones del 68 y del 95. Representaba la bravura, el desafío y la intrepidez de los que cayeron luchando en la contienda del 68.

30 Enrique Loynaz del Castillo, "Discurso leído por el Académico de Número” mayor general, en la sesión pública celebrada en La Constituyente de Jimaguayú, el 16 de septiembre de1952. Imprenta El Siglo XX, La Habana, p. 12.
202 Con ternura de hijo quiere el cubano bueno a Costa Rica Edelmis Cristina Reyes Quiñones Alberto Matos Guerra

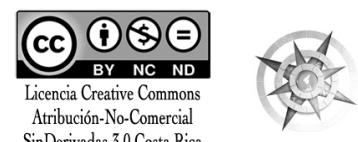


por este pueblo venturoso, en cuyo hogar me he sentado con mi trabajo y mi corazón”. Escribía más adelante:

Dejaré para servir a Costa Rica el bordón del desterrado que puso en mis manos la enemiga de la libertad; pondré a un lado mis rebeldías de la patria nativa para fijar la vista en el porvenir amplio y despejado de esta tierra singularmente favorecida por la naturaleza, y en la carta libérrima de derechos de su República hermosa: soy de la patria que me alberga y como costarricense escribo. Estará siempre mi pluma humilde al servicio de la libertad, en Costa Rica como en Cuba [... $]^{31}$

Antes había escrito la narración chorotega Las perlas de Nicoya (véase anexo 5) y el siguiente poema, que le abrieron las puertas en San José.

\section{$[\ldots]$}

De Costa Rica vi el hermoso cielo vestirse de zafir, y el alba pura vi de luz y carmin en verde suelo que ofrece al horizonte su hermosura.

Yo crucé solitario el océano buscando un pueblo, la virtud por guia, y hogares vi como el hogar cubano en esta hermana de la patria mía.

\section{$[\ldots]$}

¡Costa Rica feliz, yo te saludo! Eres un paraiso entre dos mares; la piedad es tu voz y honor tu escudo y tu virtud laureles y azahares.

En cada corazón halle un amigo quien tu luz de volcanes ha mirado, sombra le den tus nubes, y un abrigo halle en tu umbral abierto al desterrado. ${ }^{32}$

En las páginas de La Prensa Libre, el Titán de Bronce, dejó su huella en artículos firmados por Loynaz del Castillo. Uno de ellos sirvió de pretexto para desencadenar el atentado de que fue víctima; asistió en la noche del 10 de noviembre de 1894 a la función del teatro Variedades. A la salida, Maceo fue atacado a tiros, resultando herido. Milagrosamente salvó la vida; médicos colombianos y costarricenses lo atendieron, entre ellos el secretario de Gobernación, doctor Juan J. Ulloa, uno de los mejores médicos de Costa Rica. Maceo agradeció el gesto.

31 La Prensa Libre, 2 de octubre de 1894; "Saludo", La Prensa Libre, 17 de octubre de 1894. Citado en Armando Vargas Araya, El Código de Maceo. El general Antonio en América Latina, Imagen Contemporánea, La Habana, 2012, pp.12 y 13.

32 "Las perlas de Nicoya" (cuento) en La Prensa Libre, 21 de octubre de 1894; "En Costa Rica" (poema) en La República, 7 de junio de 1894, citado en Vargas Araya, El Código de Maceo...pp.13 y 14. 
El 14 de noviembre de ese año, le escribió una carta a don Rafael Iglesias, presidente, donde le refiere que:

[...] sobrevino la agresión, y fui atacado por la espalda. Puedo expresarle que ni antes ni después de la herida que recibí, hice uso del arma de fuego que de costumbre llevaba conmigo, por temor de hacer daño a las personas inocentes que cruzaban la calle en esos momentos del ataque, entre las cuales había muchas señoras.

[...] tratamos de cumplir nuestra misión ${ }^{33}$-le expresaba más adelante- he respetado y respetaré siempre la hospitalidad de este país, y he mantenido y espero mantener cordiales relaciones con muchos miembros de la colonia española.

Maceo y Loynaz creyeron siempre en la validez de podremos equivocarnos; pero se puede en el hogar de un pueblo hospitalario emitir una opinión honrada y se puede -cuando se es hispanoamericanosentirse en Costa Rica con el amor y la libertad de la familia". ${ }^{34}$
Maceo hubo de relacionarse en poco tiempo con muchas personas. Fue conocido y apreciado por el pueblo. La casa de los cubanos José y Enrique Boix y de Eduardo Pochet, en San José, se convertirían en lugares seguros para todos los exiliados que arribasen al país.

Frank Agramonte quien fue comisionado para entregar en Costa Rica la carta dirigida por Martí a Maceo, en la que aquel ponía en conocimiento del general oriental su condición de subordinado a las órdenes de Flor Crombet era portador también de una misiva de Máximo Gómez, en la que éste daba todo su apoyo a la decisión del delegado del Partido Revolucionario Cubano ${ }^{35}$.
33 "Nuestra misión" en La Prensa Libre, 10 de noviembre de 1894, ibid., p.17.

34 Ídem, pp.20 y 21.
35 José Luciano Franco, Maceo. Apuntes para una historia de su vida. La Habana, Editorial de Ciencias Sociales, 1975, t. II. p.93. 


\section{Francisco Adolfo (Flor) Crombet Tejera}

El mayor general Flor Crombet, ${ }^{36}$ era uno de los colonos de La Mansión; que junto con Maceo organizaría la futura expedición a la Isla. (Véase anexo 2).

Crombet fue el único de los altos jefes cubanos que contrajo nupcias con una costarricense, la joven nicoyana Elena Castillo Baltonado; y de este matrimonio nacieron dos hijos mansioreños: Flora del Rosario y Francisco Adolfo Flor.

Sostuvo, antes del matrimonio, relaciones con dos jóvenes costarricenses -Brígida y Eduviges-, y con cada una tuvo un hijo varón.

36 Nació en El Cobre, Santiago de Cuba, Oriente, el 17 de septiembre de 1851. Combatiente de las tres guerras. En 1890 tuvo una activa participación en la frustrada conspiración conocida como La Paz del Manganeso. Descubierto, se vio obligado a salir hacia Costa Rica, desde donde colaboró en la organización del Plan Fernandina. Fracasado éste, partió de Puerto Limón, Costa Rica, el 25.3.1895, en el vapor Adirondack, al frente de 22 expedicionarios, entre los cuales se encontraban los hermanos Antonio y José Maceo. Después de hacer escala en Kingston, Jamaica, se dirigieron a la isla Fortuna, en las Bahamas, donde abordaron la goleta Honor. Desembarcaron el 1.4.1895 por Duaba, cerca de Baracoa, Oriente, siendo tenazmente perseguidos por el enemigo. El día 8, un encuentro con una emboscada montada por los guerrilleros, hizo que el grupo se dispersara y dos días después, el 10, Crombet cayó combatiendo en Alto de Palmarito, Baracoa.

\section{Regreso a Cuba}

El general Juan Bautista Quirós les entregó a los caudillos Maceo, Crombet y Cebreco once rifles costarricenses, contribuyendo así en forma material a aquella heroica empresa. Además, solicitó por su influencia un carro a la Empresa del Ferrocarril para que trasladara secretamente a Maceo y demás revolucionarios desde San José hasta Mohín, adonde llegaron a tiempo los patriotas para embarcar hacia Jamaica. Horas antes de zarpar le devolvía los dos revólveres de la Comandancia de Plaza al general, que eran propiedad del gobierno; pero éste le había prestado el suyo, que era de puño de plata con las iniciales JBQ, marca Smith \& Weston; se lo habían obsequiado en Nueva York. ${ }^{37}$

37 En el año 1934, el general Loynaz del Castillo, ministro de Cuba en Costa Rica, en su residencia del Barrio de Amón, la tarde en que fueron depositados en la tumba los restos del ilustre desaparecido el general don Juan Bautista Quirós, consideraba un deber expresarle al redactor del Dominical: [...] fueron estos once rifles costarricenses como once chispas encendieron la llama de la independencia de Cuba, comprados con dinero del general Quirós, con dinero de un costarricense ilustre, los primeros que dispararon para llamar a filas a los hombres que tenían que cumplir el mandato de sus conciencias [...] gracias a sus influencias los emigrados cubanos pudieron salir del territorio costarricense sin que se les molestara, el General logró que el vapor 'Lagonda' arribara hasta la playa de Mohín y alzara a los soldados de la gesta bravía”. Dominical, año III, núm. 111, 11 de noviembre de 1934. Publicado por Compañía Publicidad Moderna, San José, Costa Rica. Tomado del Archivo Nacional de la 
Maceo quería tener el honor de devolvérselo algún día en el Palacio Nacional de La Habana, en la fiesta solemne de la República, al triunfar la Revolución. En la despedida, estrechó entre sus brazos al heroico y bravo amigo, diciéndole que llevara el revólver con sus iniciales, convencido de que en sus manos sería siempre el mejor símbolo de su cariño hacia la causa de la independencia. El recuerdo de los cubanos para este general tiene que ser eterno y para reconocimiento sincero y legítimo de toda esa grandeza de sus actos le fue otorgada a don Juan Bautista la condecoración Carlos Manuel de Céspedes del Castillo.

El 15 de marzo de 1895, partió de Puerto Limón el navío Adirondack con destino a Nueva York, haciendo escala en Jamaica para montar varias decenas de pasajeros. En Jamaica quedan los componentes de una expedición dirigida por el PRC y organizada y comandada por el Mayor General Flor Crombet, como jefe de mar y el mayor general Antonio Maceo como jefe de tierra. (Véase anexo 3). Al mando de la embarcación iba el capitán J. W. Sanson, norteamericano de filiación masónica, al igual que la mayoría de los patriotas cubanos.

República de Cuba, Fondo Donativos y Remisiones, Costa Rica. (Documentos relativos al general Antonio Maceo), año 1934, legajo: 101, núm. de orden 34.
Era el inicio de un azaroso itinerario que los convertiría en la primera expedición revolucionaria en llegar a Cuba durante la última guerra de independencia. La nave dejó a los patriotas en la isla Fortuna, en las Bahamas, donde abordaron la goleta Honor para desembarcar por Duaba, Baracoa, el 1 de abril de 1895.

El 10 de abril cayó el general Flor Crombet en combate fiero con los Indios de Yateras. Al escuchar los disparos, Antonio, separado de ese grupo, afirma: Ese que se bate es Flor.

El General Juan Bautista Quirós no los olvidó nunca, siguió la trayectoria de sus aguerridos combatientes, conoció la muerte temprana del valiente Flor Crombet, admiró la gesta magnífica de la Invasión realizada por Maceo y enlutó su corazón para toda la vida, cuando supo que su amigo fraterno había caído en combate el 7 de diciembre de 1896.

Atrás quedaba toda una generación de cubanos en espera de la patria que aquellos valientes tratarían de conquistar. Entre las familias que quedaron en La Mansión después de la partida de Maceo y sus colegas estaban los Milanés y Quesada, los Santiesteban, los González Balán, los Muñoz, los Quesada Galván y los González Acosta, entre otros. 
Meses después, en las filas insurrectas estarían presentes dos combatientes costarricenses: Francisco Rosales y Ramón Corrales Bagantes; este último natural de San José, ascendido a teniente el 17 de noviembre de 1895, fecha en que ingresó al Ejército Libertador.

A finales de 1895, el matancero Joaquín Alsina y Espinosa fue nombrado representante oficial de la República de Cuba en Armas ante el gobierno de Costa Rica. Posteriormente, fue recibido por el presidente de la república Rafael Iglesias, quien tuvo palabras de elogio para los jefes cubanos y para la colonia cubana de allí.

\section{Conclusiones}

Costa Rica resultó ser, para un importante grupo de cubanos decididos a luchar por la independencia de su país, mucho más que el lugar donde guarecerse y esperar por el retorno a la patria. Fue el territorio que los acogió como hijos, que les permitió continuar una vida digna, organizarse y hacer surgir un pedazo de Cuba en tierra hermana, destacándose Antonio Maceo, la figura más universal de los cubanos en el siglo XIX. Fue el primer negro recibido por el presidente de Costa Rica.
La casa que se conoció como La Mansión y dio nombre a la colonia ya no existe; pero la descendencia de esas familias cimentó el amor, cultivó su historia, conservó su identidad, sus costumbres, y es un pueblo donde casi todos los que allí viven, son herederos de aquellos luchadores cubanos.

Gracias a la decisión del gobierno costarricense de cederles tierras a esas familias, se constituyó la única colonia cubana mambisa en el mundo, fuera de las fronteras de nuestro país.

Nuestros pueblos quedaron hermanados no sólo por lazos de amistad y solidaridad de aquellos años cruciales, sino también por vínculos sanguíneos. Los apellidos Acosta, Agüero, Boix, Boza, Calleja, Calzada, Céspedes, Duque, Espinal, González, Martín, Mendiola, Miranda, Odio, Olivares, Pérez, Pochet, Prado, Renaud, Revilla, Rosabal, Valiente, Varona, comunes hoy en Costa Rica, llegaron con aquellos exiliados cubanos. ${ }^{38}$

Después de 120 años que las playas de Puerto Limón vieran partir a los hermanos Maceo y a Flor Crombet rumbo a su patria para hacer cambiar el curso de la historia, La Mansión o La Mansión de Maceo, como también se le conoce, es

38 Armando Vargas Araya, Ser agradecidos, Costa Rica, El País, 30 de marzo de 2009.

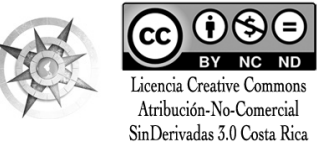


un distrito de Nicoya con más de seis mil habitantes.

La escuela primaria de este lugar se llama Antonio Maceo Grajales, y en una de las mangas del uniforme sus alumnos llevan la imagen del Titán de Bronce. La estrofa final del himno del plantel dice: "Nuestro ideal es ardiente deseo / de alcanzar una cima preciosa / nos protege una sombra gloriosa / bajo el nombre de Antonio Maceo.”

Eterno y permanente agradecimiento al pueblo de Costa Rica; y culminamos citando la frase de nuestro Apóstol, José Martí, que da título a este trabajo [...] Con ternura de hijo quiere el cubano bueno a Costa Rica. 


\section{Anexo 1}

\section{Clubes fundados en Costa Rica ${ }^{39}$}

\begin{tabular}{l|l|l}
\multicolumn{1}{c|}{ Año } & \multicolumn{1}{|c|}{ Lugar } & \multicolumn{1}{c}{ Nombre } \\
\hline \multirow{4}{*}{1895} & \multirow{4}{*}{ San José } & Hermanos Maceo \\
\cline { 3 - 3 } & & General Maceo \\
\cline { 3 - 3 } & & Hermanas de María Maceo \\
\cline { 3 - 3 } & & Costarricense/José Marti \\
\cline { 3 - 3 } & & El Pabellón Cubano \\
\cline { 3 - 3 } & Heredia & El Grito de Yara \\
\cline { 3 - 3 } & Matina & Cuba Libre \\
\cline { 3 - 3 } & San Ramón & Bolivar \\
\hline & Nicoya & Crombet-Borrero
\end{tabular}

\begin{tabular}{|c|c|c|c|}
\hline Año & Lugar & Nombre & Presidido por \\
\hline \multirow{19}{*}{1897} & \multirow{6}{*}{ San José } & Hermanas de María Maceo & Doña María C. de Maceo \\
\hline & & Hermanos Maceo & Don Santiago Güell \\
\hline & & Costarricense José Martí & Don Joaquín Alsina \\
\hline & & Obrero El Pabellón Cubano & Don Emilio Artavia \\
\hline & & Infantil Recuerdo a Martí & Srta. Julia Pérez \\
\hline & & General Maceo & Don Prudencio Odio \\
\hline & San Marcos & General Francisco de Miranda & Don Marcelino Valverde \\
\hline & Heredia & El Grito de Yara & Lic. Don J. Federico González \\
\hline & Alajuela & José de la Luz y Caballero & Don Tranquilino Chacón \\
\hline & \multirow{2}{*}{ Grecia } & Señoras de Agramonte & Doña Eulogia R. de Maroto \\
\hline & & Carlos Manuel & Don Pedro Barahona \\
\hline & San Ramón & Bolivar & Don Luis Rodríguez \\
\hline & Puntarenas & Mariscal Sucre & Don Miguel H. Céspedes \\
\hline & \multirow{2}{*}{ Nicoya } & Señoras Cubanas y Nicoyanas & Doña Cecilia de González \\
\hline & & Crombet- Borrero & Don Rafael V. Milanés \\
\hline & Cartago & Punta Brava & Don Alejandro Guzmán \\
\hline & Paraíso & Maceo resucitado & Presbitero Don Juan Garita \\
\hline & Matina & Cuba Libre & Don Pablo Pérez \\
\hline & Limón & Brigadier Crombet & Don José Arrasty \\
\hline
\end{tabular}

39 Información tomada y cotejada de Mario Oliva Medina, José Martí en la historia y la cultura costarricenses, y del Archivo Nacional de la República de Cuba, fondo Donativos y Remisiones, caja 101, núm. 27. 


\section{Anexo 2}

\section{Encuentro de José Martí y Antonio Maceo (septiembre de1893)}

- Reunión decisiva para consolidar el éxito de la Guerra Necesaria; que se preparaba. Se realizó a mediados de septiembre de 1893, en la República de Costa Rica, adonde viajó Martí con esos objetivos.

- La reunión de los dos patriotas se prolongó varios días, durante los que ambos analizaron la situación existente en Cuba y los resultados de los preparativos y tareas que llevaban a cabo Martí, Gómez y otros patriotas para preparar la guerra. Como resultado de esta reunión, quedó sellado el compromiso del mayor general Antonio Maceo y Grajales de incorporarse él y los suyos al proyecto martiano, lo que constituyó un valioso aporte para la guerra que preparaba José Martí. ${ }^{40}$

40 Diccionario Enciclopédico de Historia Militar de Cuba primera parte 1510-1898, t. III Expediciones Navales. Acontecimientos político-militares, pp. 96 y 97. Bibl: 62; 73 (III)/7-10; 87.

210 Con ternura de hijo quiere el cubano bueno a Costa Rica Edelmis Cristina Reyes Quiñones Alberto Matos Guerra
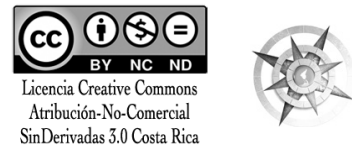


\section{Anexo 3}

\section{Expedición que trajo a Cuba a Maceo y a sus colaboradores}

\section{CROMBET - MACEO ${ }^{41}$ ADIRONDACK - HONOR 1.4.1895}

Estuvo dirigida por el Partido Revolucionario Cubano, organizada y comandada por el Mayor General Flor Crombet como jefe de mar, y trajo al mayor general Antonio Maceo como jefe de tierra. En total, vinieron veintitrés expedicionarios, entre ellos los generales Antonio y José Maceo y Flor Crombet, los coroneles Agustín Cebreco y Adolfo Peña (colombiano); los tenientes coroneles Silverio Sánchez Figueras, Patricio Corona, Arcid Duverger, José M. Arseno (dominicano), José Palacios y Alberto Boix, y además dos comandantes, cinco capitanes, tres tenientes (incluido Frank Agramonte: comisionado enviado por Martí con el dinero para la expedición) y dos subtenientes.

Trajeron 13 fusiles con 75 cartuchos cada uno, 23 revólveres y 15 machetes. El financiamiento se realizó mediante lo recaudado por el PRC y su costo fue superior a los $\$ 3$ 000. Zarparon de Puerto Limón, en Costa Rica, el 25 de marzo de1895, con 11 fusiles y el resto del armamento, en el vapor inglés de pasajeros Adirondack, cuyo capitán era J. W. Sanson, y el día 27 arribaron a Kingston, Jamaica, donde se quedó la esposa de José Maceo, Elena González, que había salido con ellos; y el vapor recogió a 55 pasajeros para Nueva York. Al llegar a Fortune Island, en las Bahamas, el día 29, los expedicionarios bajaron a tierra y lograron, por gestiones del vicecónsul norteamericano, Mr. Farrington, conseguir la goleta Honor, de 18 toneladas de capacidad, cuyo capitán era Salomón Key, así como a la tripulación; y adquirieron 2 fusiles más. De aquí salieron el día 30 y, después de una tormenta tropical seguida de una gran calma, frente a Gran Inagua, pusieron rumbo a Cuba. Desembarcaron en la madrugada del 1 de abril de 1895, en Duaba, Baracoa, costa norte de Oriente, después de hacer encallar en la costa la goleta y virarse ésta. Los expedicionarios fueron atacados y perseguidos con saña por numerosas tropas españolas de línea y guerrilleros, que les causaron sensibles bajas, incluido Flor Crombet; solo 9 de ellos lograron reunirse con las tropas insurrectas, entre ellos Antonio y José Maceo.

41 Ibid. pp. 53-54 Bibl: 3/39-41; 16/186; 22/172; 26/632; 28(2)/1065-1067; 34/177; 43/95-99 y 103; 46/26-27; 53(VI)/266-269;55/56; 71/64; 80/522; 90/9-12 y 53; 92/+5; 94(2)/1340-1342; 96/50-84.

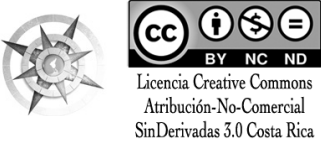




\section{Anexo 4}

\section{Himno Invasor}

\section{Compositor: General Enrique Loynaz del Castillo}

iA las Villas valientes cubanos:

A Occidente nos manda el deber De la Patria a arrojar los tiranos ¡A la carga: a morir o vencer!

De Martí la memoria adorada nuestras vidas ofrenda al honor y nos guía la fúlgida espada de Maceo, el Caudillo Invasor. Alzó Gómez su acero de gloria, y trazada la ruta triunfal, cada marcha será una victoria: la victoria del Bien sobre el Mal.

¡Orientales heroicos, al frente: Camagüey legendaria avanzad: ¡Villareños de honor, a Occidente, por la Patria, por la Libertad! De la guerra la antorcha sublime en pavesas convierta el hogar; porque Cuba se acaba, o redime, incendiada de un mar a otro mar.

A la carga escuadrones volemos, Que a degüello el clarín ordenó, los machetes furiosos alcemos, ¡Muera el vil que a la Patria ultrajó! 


\section{Anexo 5}

\section{Las perlas de Nicoya}

\section{General Enrique Loynaz del Castillo}

\section{Autor de los versos}

Cuando el alba rasgó la densa bruma vi en la playa poética guirnalda y el mar azul con su rizada espuma do esparce su fulgor una esmeralda.

\section{De Costa Rica vi el hermoso cielo} vestirse de zafir, y el alba pura vi de luz y carmin en verde suelo que ofrece al horizonte su hermosura.

Yo crucé solitario el océano

buscando un pueblo, la virtud por guia, y hogares vi como el hogar cubano en esta hermana de la patria mía.

La hermana triste que el recuerdo evoca, abatida sultana entre palmares, al siervo abriga y la arrogancia loca del dueño hambriento que usurpó sus lares.
Ya lejos de mi Cuba me destierra

de mi pecho la altiva rebeldia: troqué la pluma por fusil de guerra y en pos de azares el honor me envia.

$Y$ he encontrado una patria y nuevas flores en esta tierra orlada de hermosura, y habla a mi oído de beldad y amores fragante brisa que sutil murmura.

\section{¡Costa Rica feliz, yo te saludo!}

Eres un paraiso entre dos mares; la piedad es tu voz y honor tu escudo y tu virtud laureles y azahares.

En cada corazón halle un amigo quien tu luz de volcanes ha mirado, sombra le den tus nubes, y un abrigo halle en tu umbral abierto al desterrado.

Amar la libertad lleva a una tumba, o al destierro infeliz, a los cubanos, hasta que en recia lid triunfe o sucumba un pueblo que maldice a sus tiranos. 